\title{
Structure and Stability of a Dimeric G-Quadruplex Formed by Cyclic Oligonucleotides
}

\author{
Joan Casals, ${ }^{1}$ Júlia Viladoms, ${ }^{1,2}$ Enrique Pedroso, ${ }^{1}$ and Carlos González ${ }^{3}$ \\ ${ }^{1}$ Departament de Química Orgànica, Universitat de Barcelona, C/. Martí i Franquès 1, 08028 Barcelona, Spain \\ ${ }^{2}$ The Skaggs Institute for Chemical Biology, The Scripps Research Institute, 10550 North Torrey Pines Road, La Jolla, CA 92037, USA \\ ${ }^{3}$ Instituto de Química Física "Rocasolano", CSIC, C/. Serrano 119, 28006 Madrid, Spain
}

Correspondence should be addressed to Enrique Pedroso, epedroso@ub.edu and Carlos González, cgonzalez@iqfr.csic.es

Received 15 January 2010; Accepted 12 March 2010

Academic Editor: Daniela Montesarchio

Copyright (c) 2010 Joan Casals et al. This is an open access article distributed under the Creative Commons Attribution License, which permits unrestricted use, distribution, and reproduction in any medium, provided the original work is properly cited.

\begin{abstract}
We have studied the structure and stability of the cyclic dodecamer $\mathrm{d}<$ pGGGTTAGGGTTA $>$, containing two copies of the human telomeric repeat. In the presence of sodium, NMR data are consistent with a dimeric structure of the molecule in which two cycles self-associate forming a quadruplex with three guanine tetrads connected by edgewise loops. The two macrocycles are arranged in a parallel way, and the dimeric structure exhibits a high melting temperature. These results indicate that cyclization of the phosphodiester chain does not prevent quadruplex formation, although it affects the global topology of the quadruplex.
\end{abstract}

\section{Introduction}

One of the most studied noncanonical DNA motifs is the Gquadruplex, where four guanines are paired through their Watson-Crick and Hoogsteen sides [1-3]. These structures are receiving substantial attention in research areas ranging from molecular biology to structural and analytical chemistry [4-6]. It has been suggested that G-quadruplexes play a role in several biological processes, such as telomere integrity, genetic recombination, transcription, or replication. In addition, they are attractive targets for drug design, especially in cancer chemotherapy [7-11]. Clear evidence of quadruplex formation in vivo has been found recently [12-14].

G-quadruplexes can fold in many ways that differ in their chain number and orientation. Whereas single $G_{n}$ tracks arrange in parallel structures, multiple $\mathrm{G}_{n}$ repeats fold with different topologies that are influenced mainly by the nucleotide sequence between $\mathrm{G}_{n}$ repeats as well as by the kind of counterion. In occasions, different topologies have been found for the same oligonucleotide in solid and solution studies.

On the other hand, cyclic oligonucleotides have emerged as interesting molecules in research for diagnosis and as therapeutic agents due to their increased nuclease resistance relative to their linear analogues $[15,16]$. These molecules are also interesting for structural studies since the conformational constraint induced by cyclization of the chain may increase the relative stability of the structure of interest [17-21]. G-quadruplexes have been used as templates for enhancing the efficiency of the synthesis of cyclic oligonucleotides. This approach takes advantage of the proximity between the two oligonucleotide termini in some quadruplex topologies to improve phosphodiester ligation [22-24].

G-quadruplex forming cyclic oligonucleotides may be interesting in a number of applications. For example, these nuclease resistant oligonucleotides can be very useful probes to study G-quadruplex interacting proteins. However, the conformational constraint induced by cyclization affects the range of structures that a G-quadruplex can adopt. For example, diagonal loops or double-chain-reversal loops are not possible in quadruplexes formed by cyclic oligonucleotides.

To gain insight on the effect of cyclization on the structure of G-quadruplexes, we have studied the structure and stability of the cyclic dodecamer $\mathrm{d}<$ pGGGTTAGGGTTA $>$, containing two copies of the human telomeric repeat. The analogous linear oligonucleotide d(TAGGGTTAGGGT) forms two interconverting dimeric structures in solution: a parallel quadruplex with double-chain-reversal loops, and 

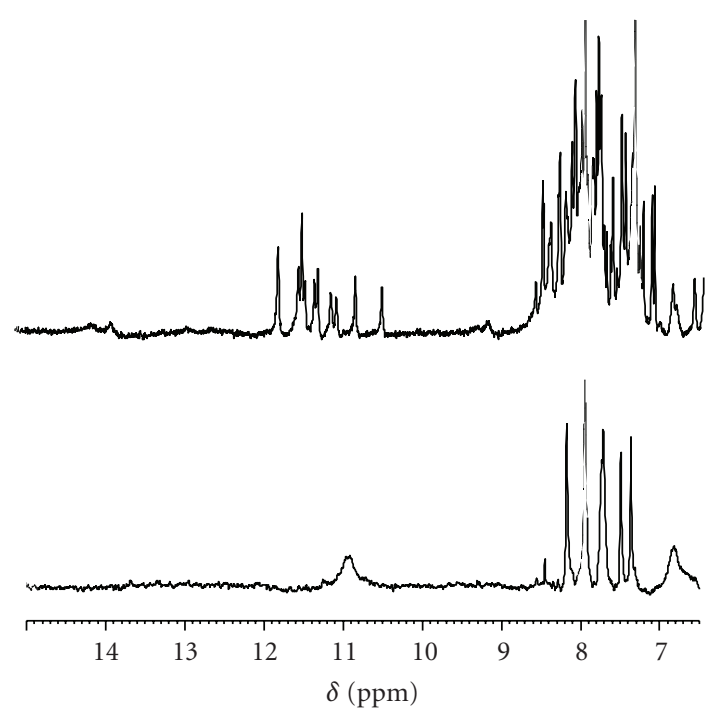

FIgURE 1: One-dimensional NMR spectra of $\mathrm{d}<$ pGGGTTAGGGTTA $>$ in $\mathrm{H}_{2} \mathrm{O}$ at $60 \mu \mathrm{M}$ (bottom) and $600 \mu \mathrm{M}$ (top) oligonucleotide concentrations (buffer conditions: $100 \mathrm{mM} \mathrm{NaCl}, 25 \mathrm{mM}$ sodium phosphate $\left.\mathrm{pH} 7, \mathrm{~T}=5^{\circ} \mathrm{C}\right)$.

an antiparallel quadruplex with edgewise loops [25]. On the other hand, the same sequence forms a parallel quadruplex with double-chain-reversal loops in the crystal (in presence of $\mathrm{K}^{+}$) [26]. A similar structural diversity has also been observed in an oligonucleotide containing four copies of the human telomeric repeat, which in $\mathrm{K}^{+}$forms an intramolecular parallel quadruplex in the crystal [26] and an antiparallel quadruplex with a diagonal and two edgewise loops in $\mathrm{Na}^{+}$containing solution [27]. Other quadruplex topologies have been observed in a variety of oligonucleotides containing different number of telomeric repeats [28-31] (see [32] for a recent review on these studies).

\section{Materials and Methods}

The synthesis of $\mathrm{d}<$ pGGGTTAGGGTTA $>$ was carried out following previously reported methods [33]. Samples for NMR experiments were prepared in $100 \mathrm{mM} \mathrm{NaCl}, 25 \mathrm{mM}$ sodium phosphate buffer $\mathrm{pH} 7$, with an oligonucleotide concentration ranging from 60 to $600 \mu \mathrm{M}$. NMR spectra were acquired in a Bruker AVANCE spectrometer operating at $600 \mathrm{MHz}$ and equipped with a cryoprobe. Two-dimensional experiments (NOESY, TOCSY, and DQF-COSY) were carried out at $5^{\circ} \mathrm{C}$ in either $\mathrm{D}_{2} \mathrm{O}$ or in $\mathrm{H}_{2} \mathrm{O} / \mathrm{D}_{2} \mathrm{O}$ 9:1. NOESY spectra were acquired with mixing times of 50,100 , and $200 \mathrm{~ms}$, and TOCSY spectra were recorded with standard MLEV-17 spin-lock sequence, and $80 \mathrm{~ms}$ mixing time. NOESY spectra in $\mathrm{H}_{2} \mathrm{O}$ were acquired with 50 and $150 \mathrm{~ms}$ mixing times. In $2 \mathrm{D}$ experiments in $\mathrm{H}_{2} \mathrm{O}$, water suppression was achieved by including a WATERGATE [34] module in the pulse sequence prior to acquisition. The spectra were processed with Topspin software and analyzed with the program Sparky [35].

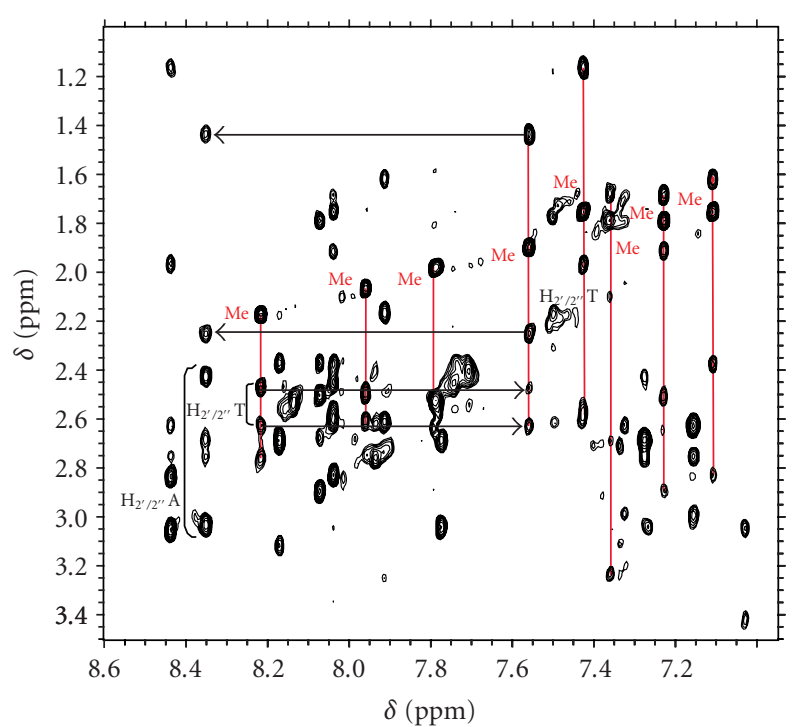

Figure 2: NOESY spectra of $\mathrm{d}<$ pGGGTTAGGGTTA $>$ in $\mathrm{D}_{2} \mathrm{O}$ ( $200 \mathrm{~ms}$ mixing time) at $600 \mu \mathrm{M}$ oligonucleotide concentration (same buffer conditions as in Figure 1). The eight thymine signals are indicated together with some informative sequential NOE contacts.

CD spectra were obtained following the change of ellipticity from $220 \mathrm{~nm}$ to $320 \mathrm{~nm}$ at different temperatures on a Jasco spectropolarimeter equipped with a Peltier temperature control used to set the temperature between $5^{\circ} \mathrm{C}$ and $90^{\circ} \mathrm{C}$. The changes in ellipticity versus temperatures were plotted and used to obtain the melting temperature. Melting experiments were recorded at $0.5^{\circ} \mathrm{C} / \mathrm{min}$ at the maximum wavelength. $\mathrm{CD}$ spectra were recorded at oligonucleotide concentrations ranging from 5 to $50 \mu \mathrm{M}$. The spectra were normalized to facilitate comparisons.

\section{Results and Discussion}

NMR spectra change dramatically upon oligonucleotide concentration. At low concentration, only six $\mathrm{H} 6 / \mathrm{H} 8$ aromatic signals are detected (as a logical consequence of the repetitive sequence), and the exchangeable proton spectrum is very broad (see Figure 1). However, at high oligonucleotide concentration the exchangeable proton spectra shows 12 narrow signals between 10.0 and $12.0 \mathrm{ppm}$, and 24 aromatic signals (corresponding to $\mathrm{H} 6 / \mathrm{H} 8$ protons) are observed in the non-exchangeable proton spectrum (see Figure 2). These data indicate the formation of an asymmetric dimer. Two fragments of the NOESY spectra in $\mathrm{D}_{2} \mathrm{O}$ are shown in Figures 2 and 3 . The NMR spectrum in these conditions exhibits narrow and well dispersed signals, which indicates that the oligonucleotide adopt a well-defined structure. However, the NMR spectra of this molecule could not be unambiguously assigned due to its highly repetitive sequence. In spite of this, many structural features can be spotted from this spectrum. First, the cross-peaks of the imino and amino protons are consistent with the presence of three G-tetrads. Secondly, as shown in Figure 3, six 


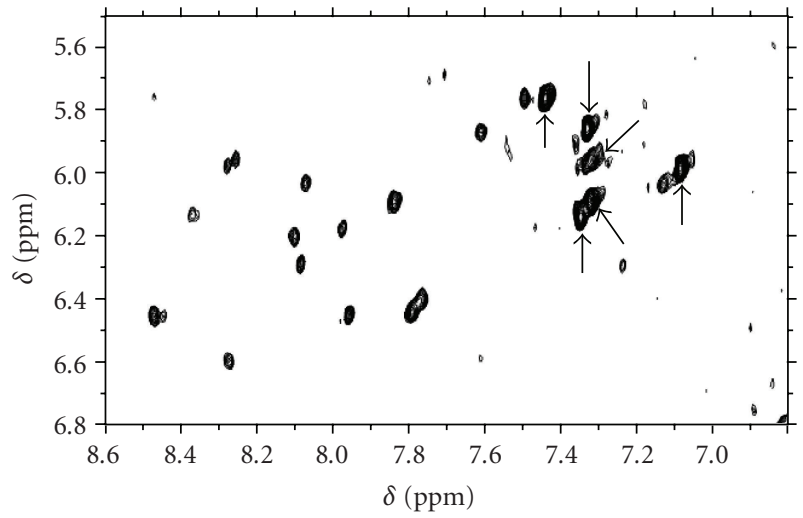

Figure 3: NOESY spectra of $\mathrm{d}<$ pGGGTTAGGGTTA $>$ in $\mathrm{D}_{2} \mathrm{O}$ (200 ms mixing time) at $600 \mu \mathrm{M}$ oligonucleotide concentration (same buffer conditions as in Figure 1). Strong H1' $-\mathrm{H} 8$ cross-peaks, characteristic of syn guanines, are indicated.

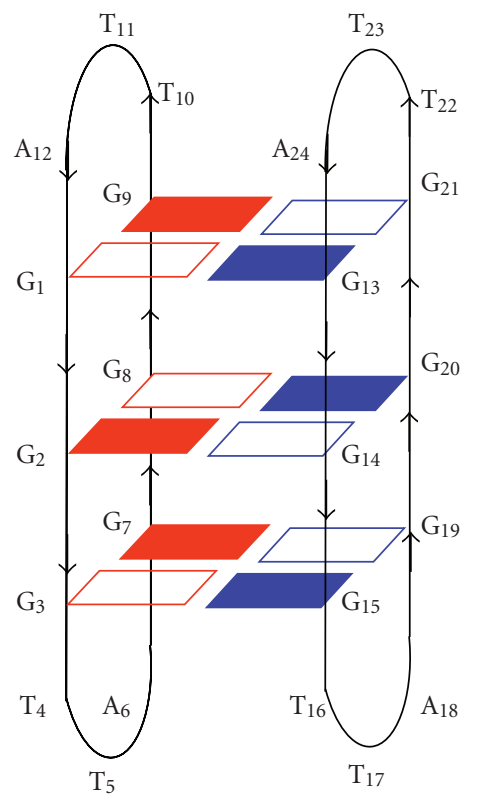

FIGURE 4: Schematic model of the dimeric structure of $d<$ pGGGTTAGGGTTA $>$, consistent with the experimental data in $\mathrm{Na}^{+}$ buffer. Guanines syn and anti are indicated with open and solid rectangles, respectively.

strong $\mathrm{H}^{\prime}{ }^{\prime}-\mathrm{H} 8$ cross-peaks are observed, indicating that the glycosidic angle of the corresponding guanines is in a syn conformation (Gs). The six remaining guanines are in an anti conformation $(\mathrm{Ga})$. Moreover, the occurrence of four steps Gs-Ga can be established from the sequential $\mathrm{H}^{\prime}{ }^{\prime} \rightarrow$ H8 NOEs steps. Finally, no Ga-Ga steps are present in this structure since no sequential NOEs are observed between guanines in anti.

All these data, together with symmetry considerations, led us to suggest a model for this structure in which two cyclic dodecamers self-associate forming an antiparallel quadruplex with three G-tetrads (Figure 4). The two macrocycles are arranged in a parallel way. Overall, the structure is similar to antiparallel quadruplexes resulting from a head-to-head association of two hairpins with "edgewise" loops.

It is interesting to compare these results with other structures of quadruplexes formed by linear oligonucleotides containing repeats of the human telomeric sequence. Different groups have shown that linear oligonucleotides containing two repeats tend to adopt antiparallel quadruplex structures in sodium buffer $[25,36]$. In the case of d(UAGGGT ${ }^{\text {Br }}$ UAGGGT) the structure is an asymmetric dimer [25], but the relative orientation of the two molecules is different than in the dimeric structure of $\mathrm{d}<$ pGGGTTAGGGTTA $>$. The distribution of $s y n$ and anti guanines is also different in both cases. In the presence of $\mathrm{K}^{+}$, linear oligonucleotides containing two repeats of the human telomere have the propensity to adopt parallelstranded structures $[25,36]$, which are obviously impossible in the case of the cyclic analogues. We must conclude that the conformational constraint induced by cyclization of the phosphodiester chain affects the topology of the quadruplex. This result is not surprising since cyclization is formally equivalent to introducing an additional nonnative loop in the sequence. The effect of loop variations in the structure and topology of quadruplex has been extensively studied by several groups [37-39].

Since many oligonucleotides containing human telomeric repeats tend to adopt different structures in presence of $\mathrm{K}^{+}$or $\mathrm{Na}^{+}$cations, we tackled the study of the effect of these two cations on the structure of $\mathrm{d}<$ pGGGTTAGGGTTA $>$. The profile of the $\mathrm{CD}$ spectra in $\mathrm{Na}^{+}$buffer was consistent with an antiparallel G-quartet architecture characterized by a positive band at $248 \mathrm{~nm}$, a positive maximum at $295 \mathrm{~nm}$, and a negative maximum at $265 \mathrm{~nm}$ (Figure 5(a)). However, in presence of $\mathrm{K}^{+}$the $\mathrm{CD}$ spectra of $\mathrm{d}<$ pGGGTTAGGGTTA $>$ changes dramatically (Figure 5(b)). The negative band at $265 \mathrm{~nm}$ disappears, and the minimum around $235 \mathrm{~nm}$ is more pronounced. In these experimental conditions the CD spectrum is not consistent with a pure antiparallel or parallel G-quadruplex, the latter presenting a characteristic positive maximum at $265 \mathrm{~nm}$ [36]. The experimental CD spectrum suggests the presence of several conformations in equilibrium. NMR spectra conducted at $500 \mu \mathrm{M}$ oligonucleotide concentration in $\mathrm{K}^{+}$buffer exhibit very broad signals (data not shown), in agreement with the occurrence of multiple conformations or aggregation. This result is not unexpected since it is well documented that $\mathrm{K}^{+}$cations favour the parallel-stranded structures, which in this case are impeded by the cyclization of the phosphodiester chain.

The thermal stability of this structure has been studied by NMR and CD experiments. CD spectra of $\mathrm{d}<$ pGGGTTAGGGTTA $>$ in $\mathrm{Na}^{+}$are characteristic of antiparallel quadruplexes (see Figure 5). Melting curves were recorded at different oligonucleotide concentrations, and thermodynamic parameters were obtained from the variation of the melting temperature with the concentration [40]. Thermodynamic parameters for dimer formation in $100 \mathrm{mM}$ $\mathrm{NaCl}$ buffer solution are $\Delta \mathrm{H}^{0}=-35 \mathrm{kcal} / \mathrm{mol}, \Delta \mathrm{S}^{0}=$ $-92 \mathrm{cal} / \mathrm{mol}$, and $\Delta \mathrm{G}_{298}^{0}=-8 \mathrm{kcal} / \mathrm{mol}$. It is interesting to compare these parameters with the values for the unimolecular quadruplex formed by analogous linear oligonucleotides 


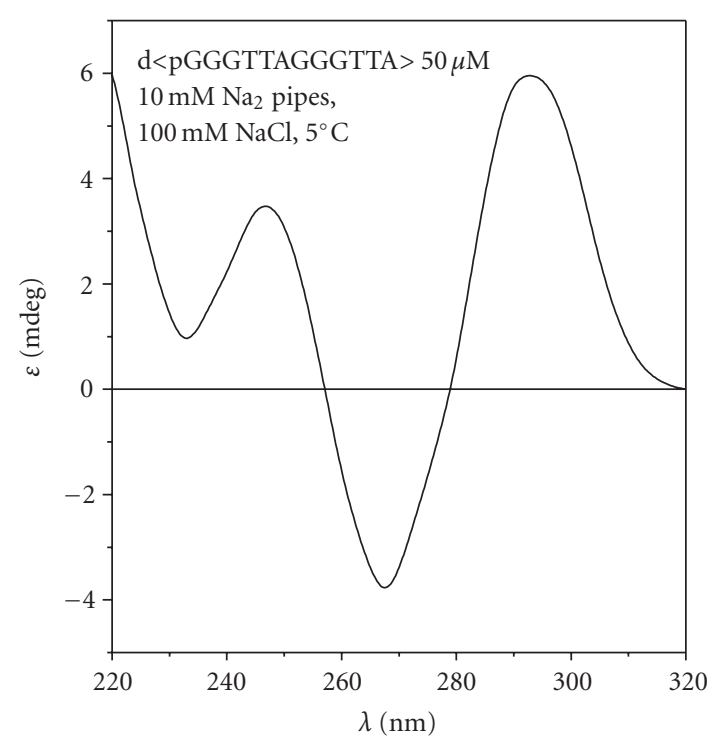

(a)

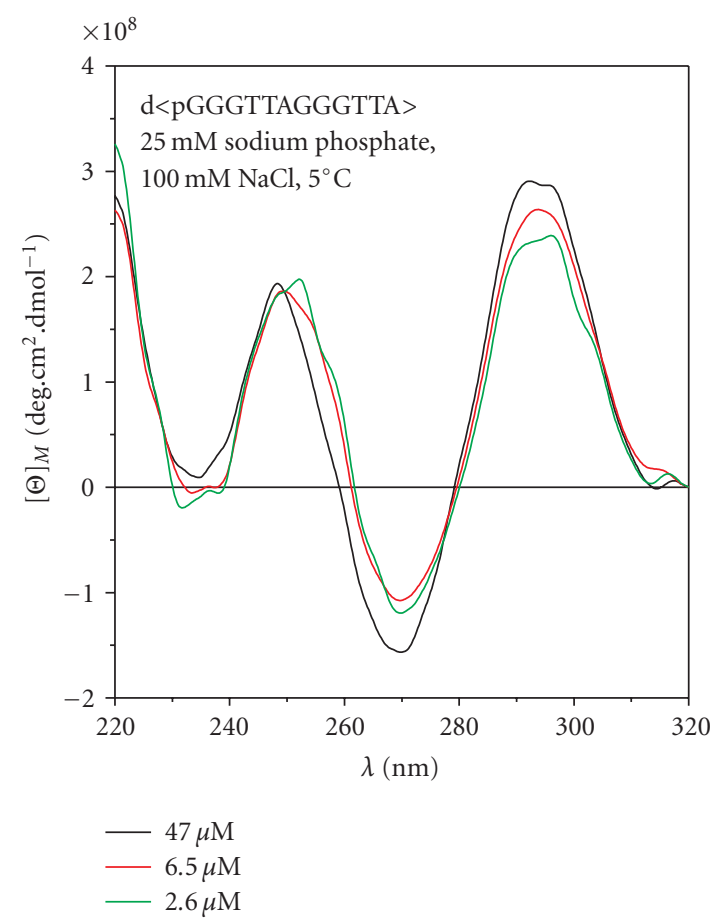

(c)

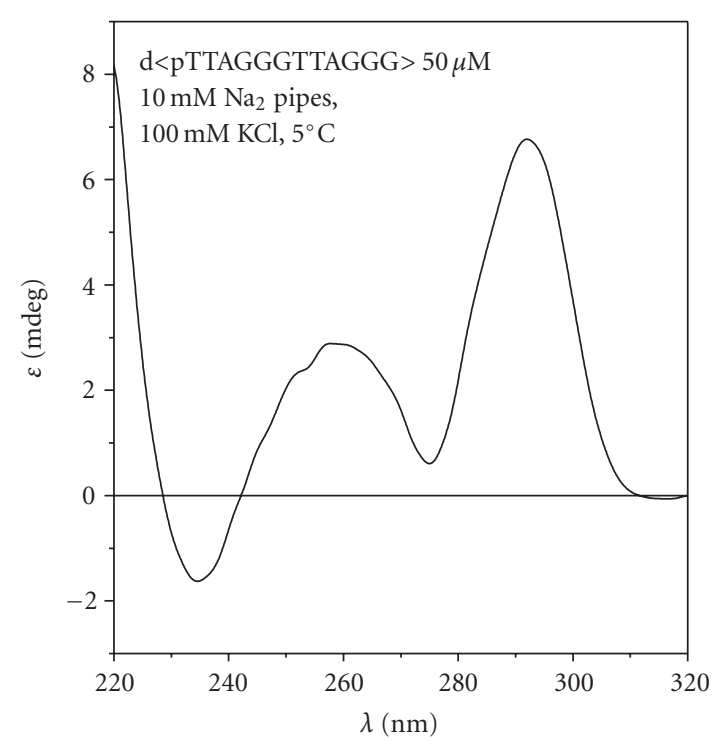

(b)

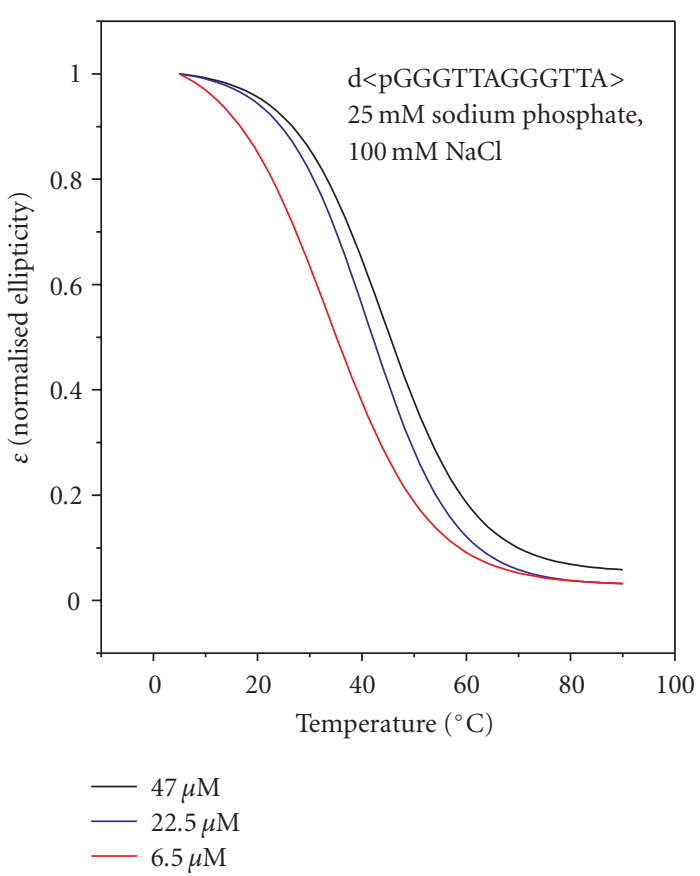

(d)

FIGURE 5: CD spectra of $\mathrm{d}<$ pGGGTTAGGGTTA > in media containing $\mathrm{Na}^{+}$(a) or $\mathrm{K}^{+}$(b). Converted to molar ellipticity CD spectra (c) and normalized melting curves (d) at different oligonucleotide concentrations in the same buffer conditions as NMR experiments.

containing four repeats of the human telomere. For example, the thermodynamic parameters for d(AGGGTTAGGGTTAGGGTTAGGG), under the same buffer conditions, are $\Delta \mathrm{H}^{0}=-54 \mathrm{kcal} / \mathrm{mol}, \Delta \mathrm{S}^{0}=-163 \mathrm{cal} / \mathrm{mol}$, and $\Delta \mathrm{G}_{298}^{0}=$ $-5.4 \mathrm{kcal} / \mathrm{mol}$ [41]. Interestingly, formation-free energy is lower for the quadruplex formed by two cyclic oligonucleotides than for the quadruplex formed by the "native" sequence with four telomeric repeats. The larger stability of the former is entropic in nature. The lower formation enthalpy in the dimer is probably a consequence of the constraint in the loops induced by the cyclization. We can conclude that "native" loops are enthalpically more stable. However, the entropic cost of forming the quadruplex through the self-association of two cyclic oligonucleotides with two repeats is lower than in the case of the folding of a linear oligonucleotide with four telomere repeats. 


\section{Conclusions}

In summary, we have shown that guanine-rich cyclic oligonucleotides can form dimeric quadruplex structures. The conformational constraint induced by cyclization of the chain does not prevent quadruplex formation but has a profound influence in the global topology and stability of the structure. Such effect must be taken into account in the potential application of cyclic G-quadruplex as molecular probes.

\section{Acknowledgments}

This work was supported by the Spanish Ministry of Science and Innovation Grant CTQ2007-68014-C02-01/02, COST project (G4-net, MP0802) and Generalitat de Catalunya grants 2009 SGR 208 and XRB.

\section{References}

[1] S. Burge, G. N. Parkinson, P. Hazel, A. K. Todd, and S. Neidle, "Quadruplex DNA: sequence, topology and structure," Nucleic Acids Research, vol. 34, no. 19, pp. 5402-5415, 2006.

[2] P. Bates, J.-L. Mergny, and D. Yang, "Quartets in G-major. The first international meeting on quadruplex DNA," EMBO Journal, vol. 8, no. 11, pp. 1003-1010, 2007.

[3] J. L. Huppert, "Four-stranded nucleic acids: structure, function and targeting of G-quadruplexes," Chemical Society Reviews, vol. 37, no. 7, pp. 1375-1384, 2008.

[4] J. T. Davis, "G-quartets 40 years later: from 5'-GMP to molecular biology and supramolecular chemistry," Angewandte Chemie International Edition, vol. 43, no. 6, pp. 668-698, 2004.

[5] D. Margulies and A. D. Hamilton, "Protein recognition by an ensemble of fluorescent DNA G-quadruplexes," Angewandte Chemie International Edition, vol. 48, no. 10, pp. 1771-1774, 2009.

[6] P. Alberti, A. Bourdoncle, B. Saccà, L. Lacroix, and J.-L. Mergny, "DNA nanomachines and nanostructures involving quadruplexes," Organic and Biomolecular Chemistry, vol. 4, no. 18, pp. 3383-3391, 2006.

[7] S. Balasubramanian and S. Neidle, "G-quadruplex nucleic acids as therapeutic targets," Current Opinion in Chemical Biology, vol. 13, no. 3, pp. 345-353, 2009.

[8] M. A. Blasco, "Telomeres and human disease: ageing, cancer and beyond," Nature Reviews Genetics, vol. 6, no. 8, pp. 611622, 2005.

[9] D. J. Patel, A. T. Phan, and V. Kuryavyi, "Human telomere, oncogenic promoter and 5'-UTR G-quadruplexes: diverse higher order DNA and RNA targets for cancer therapeutics," Nucleic Acids Research, vol. 35, no. 22, pp. 7429-7455, 2007.

[10] D. Monchaud and M.-P. Teulade-Fichou, "A hitchhiker's guide to G-quadruplex ligands," Organic and Biomolecular Chemistry, vol. 6, no. 4, pp. 627-636, 2008.

[11] B. Gatto, M. Palumbo, and C. Sissi, "Nucleic acid aptamers based on the G-quadruplex structure: therapeutic and diagnostic potential," Current Medicinal Chemistry, vol. 16, no. 10, pp. 1248-1265, 2009.

[12] K. Paeschke, T. Simonsson, J. Postberg, D. Rhodes, and H. J. Lipps, "Telomere end-binding proteins control the formation of G-quadruplex DNA structures in vivo," Nature Structural and Molecular Biology, vol. 12, no. 10, pp. 847-854, 2005.
[13] M. L. Duquette, P. Handa, J. A. Vincent, A. F. Taylor, and N. Maizels, "Intracellular transcription of G-rich DNAs induces formation of G-loops, novel structures containing G4 DNA," Genes and Development, vol. 18, no. 13, pp. 1618-1629, 2004.

[14] N. Maizels, "Dynamic roles for G4 DNA in the biology of eukaryotic cells," Nature Structural and Molecular Biology, vol. 13, no. 12, pp. 1055-1059, 2006.

[15] E. T. Kool, "Circular oligonucleotides: new concepts in oligonucleotide design," Annual Review of Biophysics and Biomolecular Structure, vol. 25, pp. 1-28, 1996.

[16] E. T. Kool, "Recognition of DNA, RNA, and proteins by circular oligonucleotides," Accounts of Chemical Research, vol. 31, no. 8, pp. 502-510, 1998.

[17] G. W. Ashley and D. M. Kushlan, "Chemical synthesis of oligonucleotide dumbbells," Biochemistry, vol. 30, pp. 29272933, 1991.

[18] J. H. Ippel, V. Lanzotti, A. Galeone, et al., "Conformation of the circular dumbbell $\mathrm{d}<$ pCGC-TT-GCG-TT $>$ : structure determination and molecular dynamics," Journal of Biomolecular NMR, vol. 6, no. 4, pp. 403-422, 1995.

[19] C.-T. Lin, Y. L. Lyu, and L. F. Liu, "A cruciform-dumbbell model for inverted dimer formation mediated by inverted repeats," Nucleic Acids Research, vol. 25, no. 15, pp. 3009-3016, 1997.

[20] N. Escaja, E. Pedroso, M. Rico, and C. González, "Dimeric solution structure of two cyclic octamers: four-stranded DNA structures stabilized by A:T:A:T and G:C:G:C tetrads," Journal of the American Chemical Society, vol. 122, no. 51, pp. 12732$12742,2000$.

[21] J. Viladoms, N. Escaja, M. Frieden, I. Gomez-Pinto, E. Pedroso, and C. González, "Self-association of short DNA loops through minor groove C:G:G:C tetrads," Nucleic Acids Research, vol. 37, no. 10, pp. 3264-3275, 2009.

[22] J. Qi and R. H. Shafer, "Covalent ligation studies on the human telomere quadruplex," Nucleic Acids Research, vol. 33, no. 10, pp. 3185-3192, 2005.

[23] T. Zhou, G. Chen, Y. Wang, Q. Zhang, M. Yang, and T. $\mathrm{Li}$, "Synthesis of unimolecularly circular G-quadruplexes as prospective molecular probes," Nucleic Acids Research, vol. 32, no. 21, article e173, 2004.

[24] J. Chen, D. Liu, A. H. F. Lee, J. Qi, A. S. C. Chan, and T. Li, "Formation of circular oligodeoxyribonucleotides on the structural basis of G-quadruplex and product analysis," Chemical Communications, pp. 2686-2687, 2002.

[25] A. T. Phan and D. J. Patel, "Two-repeat human telomeric $\mathrm{d}$ (TAGGGTTAGGGT) sequence forms interconverting parallel and antiparallel G-quadruplexes in solution: distinct topologies, thermodynamic properties, and folding/unfolding kinetics," Journal of the American Chemical Society, vol. 125, no. 49, pp. 15021-15027, 2003.

[26] G. N. Parkinson, M. P. H. Lee, and S. Neidle, "Crystal structure of parallel quadruplexes from human telomeric DNA," Nature, vol. 417, no. 6891, pp. 876-880, 2002.

[27] Y. Wang and D. J. Patel, "Solution structure of the human telomeric repeat d[AG3(T2AG3)3] G-tetraplex," Structure, vol. 1, no. 4, pp. 263-282, 1993.

[28] N. Zhang, A. T. Phan, and D. J. Patel, “ $(3+1)$ assembly of three human telomeric repeats into an asymmetric dimeric G-quadruplex," Journal of the American Chemical Society, vol. 127, no. 49, pp. 17277-17285, 2005.

[29] A. T. Phan, V. Kuryavyi, K. N. Luu, and D. J. Patel, "Structure of two intramolecular G-quadruplexes formed by natural human telomere sequences in $\mathrm{K}^{+}$solution," Nucleic Acids Research, vol. 35, no. 19, pp. 6517-6525, 2007. 
[30] A. T. Phan, K. N. Luu, and D. J. Patel, "Different loop arrangements of intramolecular human telomeric (3+1) Gquadruplexes in $\mathrm{K}^{+}$solution," Nucleic Acids Research, vol. 34, no. 19, pp. 5715-5719, 2006.

[31] J. Dai, M. Carver, C. Punchihewa, R. A. Jones, and D. Yang, "Structure of the hybrid-2 type intramolecular human telomeric G-quadruplex in $\mathrm{K}^{+}$solution: insights into structure polymorphism of the human telomeric sequence," Nucleic Acids Research, vol. 35, no. 15, pp. 4927-4940, 2007.

[32] A. T. Phan, "Human telomeric G-quadruplex: structures of DNA and RNA sequences," FEBS Journal, vol. 277, no. 5, pp. 1107-1117, 2010.

[33] E. Alazzouzi, N. Escaja, A. Grandas, and E. Pedroso, "A straightforward solid-phase synthesis of cyclic oligodeoxyribonucleotides," Angewandte Chemie International Edition, vol. 36, no. 13-14, pp. 1506-1508, 1997.

[34] M. Piotto, V. Saudek, and V. Sklenár, "Gradient-tailored excitation for single-quantum NMR spectroscopy of aqueous solutions," Journal of Biomolecular NMR, vol. 2, no. 6, pp. 661665, 1992.

[35] D. T. Goddard and G. Kneller, SPARKY 3, University of California, San Francisco, Calif, USA, 2003.

[36] I. N. Rujan, J. C. Meleney, and P. H. Bolton, "Vertebrate telomere repeat DNAs favor external loop propeller quadruplex structures in the presence of high concentrations of potassium," Nucleic Acids Research, vol. 33, no. 6, pp. 20222031, 2005.

[37] M. Webba da Silva, M. Trajkovski, Y. Sannohe, N. Ma'ani Hessari, H. Sugiyama, and J. Plavec, "Design of a G-quadruplex topology through glycosidic bond angles," Angewandte Chemie International Edition, vol. 48, no. 48, pp. 9167-9170, 2009.

[38] P. Hazel, G. N. Parkinson, and S. Neidle, "Predictive modelling of topology and loop variations in dimeric DNA quadruplex structures," Nucleic Acids Research, vol. 34, no. 7, pp. 21172127, 2006.

[39] N. Smargiasso, F. Rosu, W. Hsia, et al., "G-quadruplex DNA assemblies: loop length, cation identity, and multimer formation," Journal of the American Chemical Society, vol. 130, no. 31, pp. 10208-10216, 2008.

[40] K. J. Breslauer, "Extracting thermodynamic data from equilibrium melting curves for oligonucleotide order-disorder transitions," Methods in Enzymology, vol. 259, pp. 221-242, 1995.

[41] J.-L. Mergny, A.-T. Phan, and L. Lacroix, "Following G-quartet formation by UV-spectroscopy," FEBS Letters, vol. 435, no. 1, pp. 74-78, 1998. 

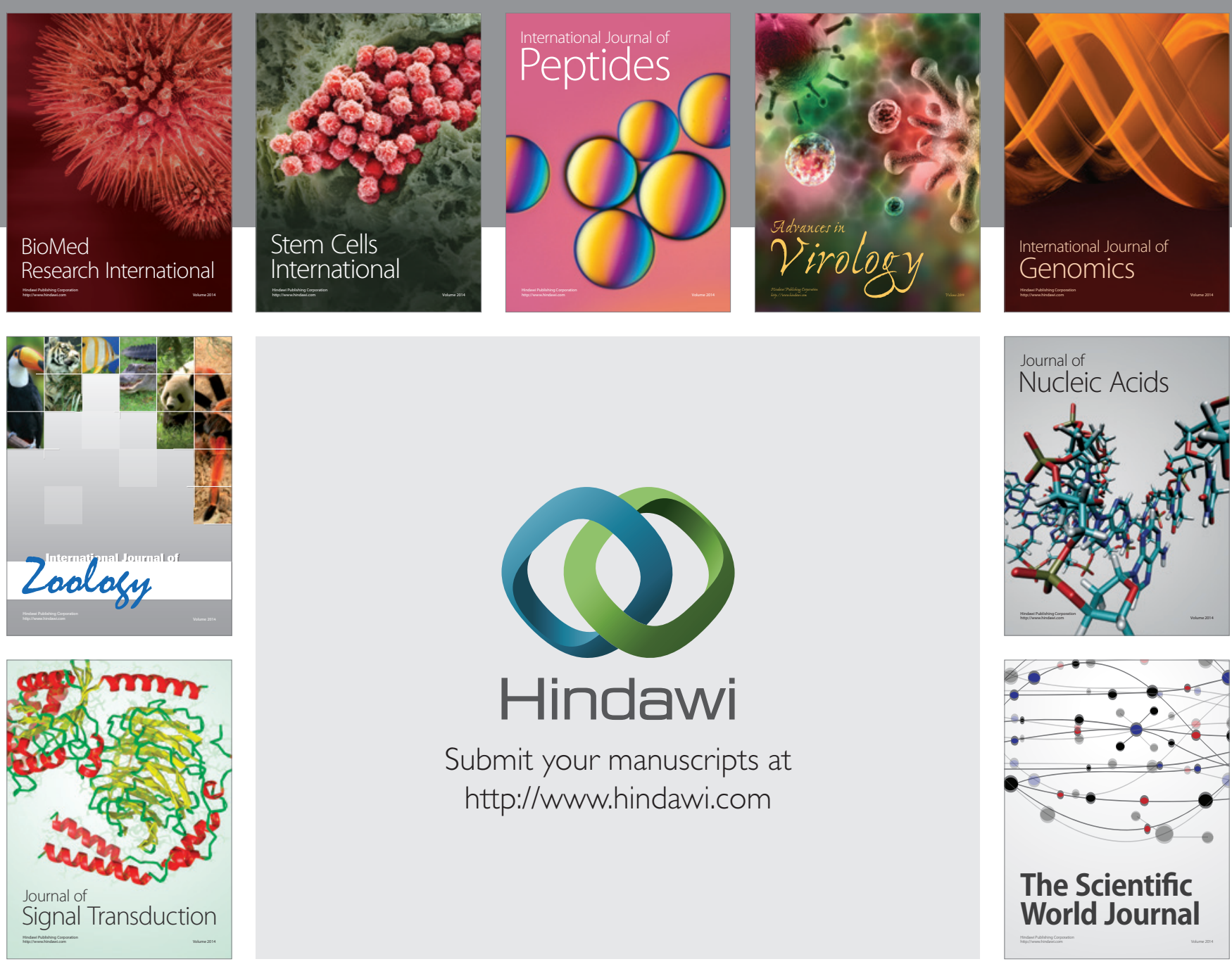

Submit your manuscripts at

http://www.hindawi.com
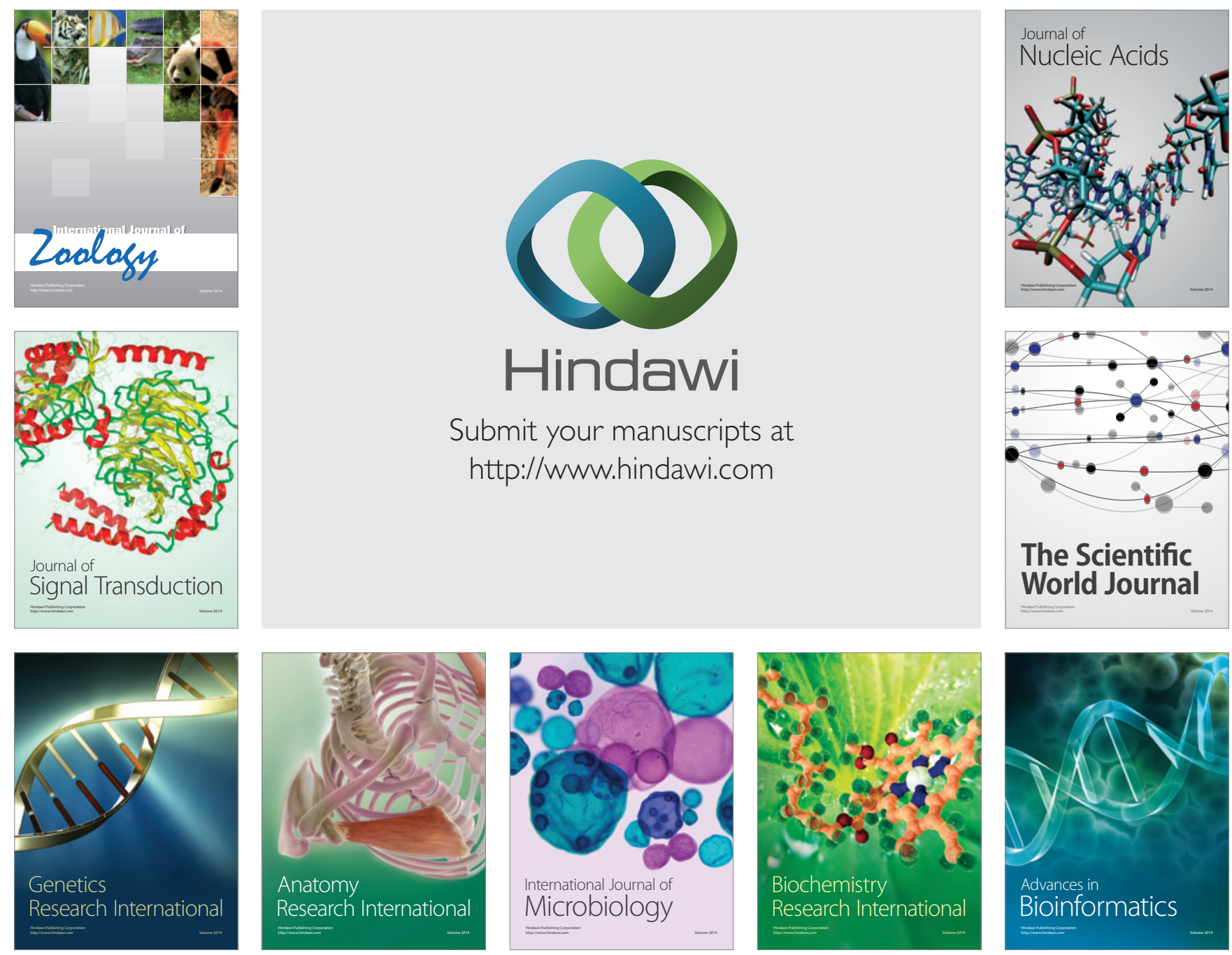

The Scientific World Journal
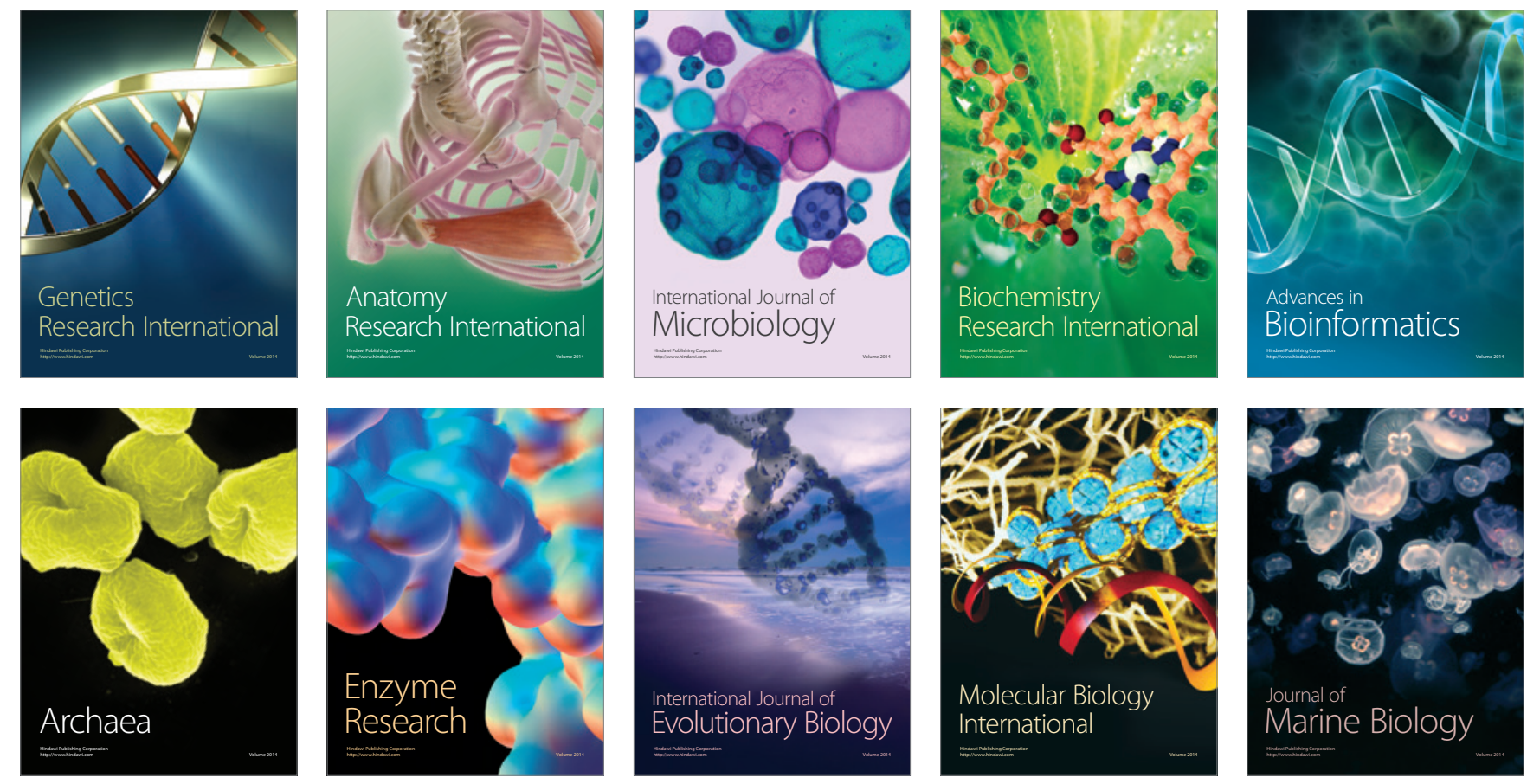